\title{
Two Novel Potentiometric Sensors for Determination of Clonidine in Some Pharmaceutical Formulation
}

\author{
H. AlRabiah ${ }^{1}$, A. Al-Majed ${ }^{1}$, M. Abounassif ${ }^{1}$ and G.A.E.Mostafa, ${ }^{1,2 *}$ \\ ${ }^{1}$ Pharmaceutical Chemistry Department, College of Pharmacy, King Saud University, P.O.Box 2457, \\ Riyadh11451, Saudi Arabia \\ ${ }^{2}$ Micro-analytical Lab., Applied organic Chemistry Department, National Research Center, Dokki, \\ Cairo, Egypt \\ *E-mail: gamal_most@yahoo.com
}

doi: $10.20964 / 2016.08 .14$

Received: 27 April 2016 / Accepted: 29 May 2016 / Published: 7 July 2016

Two novel membrane sensors with cylindrical configuration for clonidine $\mathrm{HCl}$ have been developed. The electroactive material incorporate $\beta$ - or $\gamma$-cyclodextrin as ionophores. Sensor 1 and 2 were fabricated utilizing $\beta$ - and $\gamma$-cyclodextrin in presence of potassium tetrakis (4-chlorophenyl)borate (KTpCIPB) as ion additive, PVC as matrix and o-nitrophenyl octyl ether (o-NPOE) as plasticizer. Both sensors showed a significant response to clonidine with near-Nernstian cationic slope of 53 and $54 \mathrm{mV} /$ decade over a relative wide dynamic range of $1 \times 10^{-2}-6.0 \times 10^{-6}$ and $1 \times 10^{-2}-5.5 \times 10^{-6} \mathrm{M}$, for sensor 1 and 2 respectively. The detection limits were $5 \times 10^{-6}$ and $3.5 \times 10^{-6} \mathrm{M}$ for sensor 1 and 2 in the $\mathrm{pH}$ range of 2-7. The developed sensors using the novel ionophores were improve the selectivity for clonidine in presence of different ions. The determination of $230.09 \mu \mathrm{g} / \mathrm{ml}$ of clonidine show good accuracy and precision (101.99 and $10.89 \%$ and 2.77 and 3.36\% respectively) for sensor $\beta$ - and $\gamma$-CD, respectively. The investigated sensors have been connected for determination of clonidine in its dosage form and contrasted with those got utilizing the HPLC technique. The sensors have been used as pointer sensors for determination of clonidine by potentiometric titration. The investigated sensors revealed good analytical characteristics include, high selectivity, fast response, long life time, good stability with high accuracy and precise .

Keywords: Clonidine $\mathrm{HCl}, \quad \beta$ - and $\gamma$-cyclodextrin, ionophore, Potentiometry

\section{FULLTEXT}

(C) 2016 The Authors. Published by ESG (www.electrochemsci.org). This article is an open access article distributed under the terms and conditions of the Creative Commons Attribution license (http://creativecommons.org/licenses/by/4.0/). 